\section{THE ERUPTION OF MATAVANU IN SAVAII, I905-6.}

THE last-issued number of the Zeitschrift der gesellschaft für Erdkunde zu Berlin contains an account of a very remarkable volcanic eruption which had been in progress for more than twelve months in September last in the island of Savaii. The volcanoes of this island had been quiet for more than a century when, in 1902, two minor outbreaks occurred, and in 1905 a greater eruption commenced, causing so much anxiety and alarm that the German Colonial Administration sent to Prof. K. Sapper, of Tübinǵen, a collection of specimens, photographs, and newspaper and other reports, from which he has compiled an account which is interesting in spite of its inevitable incompleteness.

The eruption was ushered in by a series of earthquakes lasting from July 25 to August 1 , 1905; at half past nine on the night of the last-mentioned date a loud detonation

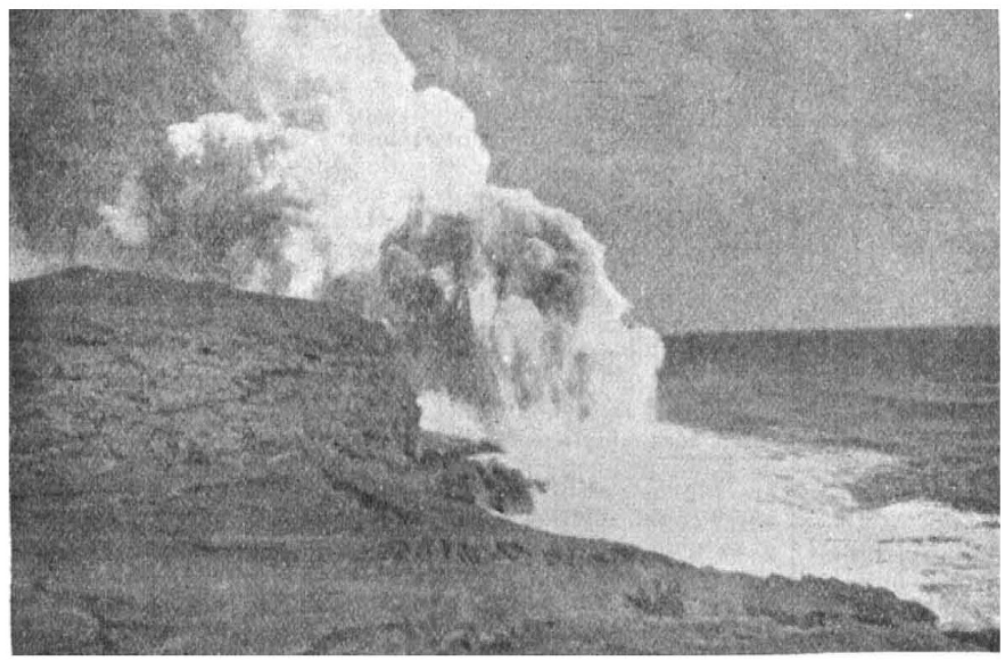

Lava flowing under its conşo'idated upper crust into the sea near Salago, September, igo6.

was heard, and shortly after "pillars of fire" were seen issuing from a valley known as Matavanu, some 12 kilometres from the coast on the north-eastern side of the island. At first the eruption was of an explosive character, and does not seem to have been very violent, as the estimates of the height to which matter was thrown do not exceed 200 metres, and the hill formed was never more than r5o metres in height. On August 9 lava began to flow, at first in small quantities, afterwards more abundantly, until it reached the coast on December 6, and flowed down to the sea at intervals up to the end of September, 1906, the date of the latest reports received by Prof. Sapper. During this period the outflow of lava seems to have been continuous, though varying in amount, and unaccompanied by any considerable degree of explosive activity.

Many people visited the volcano during the eruption, and an interesting account by Dr. Greve! is reprinted from the local newspaper; his party made the ascent on April 23 last, over the crust of the lava stream, which was smooth and easily traversed, and cool enough for the Samoans who accompanied him to walk over it. The solid surface of the lava stream was broken at intervals by vent holes, the one nearest the crater being at first mistaken for a parasitic cone, as the crust of the lava rose in a gentle convexity to the orifice, which was much smaller in diameter than the cavity underneath. Thick, sulphurous vapours prevented any sight into the cavity, and large stones thrown in gave no clue to its depth, as their fall was unheard. Four of these vent holes were examined, which repeated the features of the first on a smaller scale, and the party then climbed to the crater by an easy ascent over the lava flow on the northern side. Owing to the drift of the south-east trade wind, no view of the crater beyond the reef. could be obtained, so Dr. Grevel and his party worked round by the east, where the surface was covered with countless bodies of moths, attracted by the glow of the crater and killed by the vapours rising from cracks in the surface of the lava flow; the same vapours had proved fatal to a flying-fox, a dove, and a sea-gull. From the southern edge a good view of the crater was obtained; it was about 300 metres in diameter, filled with a lake of molten lava in gentle ebullition, caused by the rise of steam bubbles, and from the centre a gentle streaming to the north commenced, which increased in rapidity until the lava disappeared in a cataract into a cloud of steam, and presumably ioined the stream over the surface of which the party had ascended.

On reaching the sea, the lava flowed out to the reef, where its end, being cooled by the surf, formed a wall between which and the coast the lava flowed quietly along the lagoon. At its end the sea was in violent ebullition, dense clouds of steam were formed, and for roo metres from the end of the flow the sea was boiling hot, and fishes, killed and cooked by this boiling sea-water, were collected and eaten by the natives. In a few places the lava flowed over the reef into the deep water outside; and where this occurred its progress was marked by violent geyser-like explosions, which were mistaken by some people for fresh volcanic eruptions, but were in reality due to steam formed under the still liquid lava. We reproduce a very striking photograph of one of these geyser-like explosions at the front of a lava stream flowing into the deep sea. The lava was remarkable for its fluidity, and issued in great quantity; according to a map attached to Prof. Sapper's paper, the area covered by the lava extends about 6 kilometres to the west and 12 kilometres to the north-east of the volcano, and has a width of from 2 kilometres to 5 kilometres; it has filled the lagoon for about 8 kilometres along the coast, destroying several villages and rendering others uninhabitable by cutting off their water supply, while several small promontories of lava were thrust forward

\section{RESEARCH IN TROPICAL MEDICINE AND HYGIENE. ${ }^{1}$}

(r) THE greater part of the first report is occupied with an elaborate menoir by Drs. Thomas and Breinl on trypanosomes, trypanosomiasis, and sleeping sickness. It comprises a description of cases of sleeping sickness, a full account of inoculation experiments with the Trypanosoma gambiense, from which the conclusion is formulated that the trypanosomes of sleeping sickness of Uganda and of the Congo Free State and of trypanosomiasis are identical, together with an account of the pathological anatomy and histology of trypanosomiasis, the action of various drugs on trypanosomes, and experiments with the trypanosomes of surra, mal de caderas, dourine, \&c.

The late Mr. Dutton and Dr. Todd contribute an important memoir on human tick fever in the Congo Free State, with an appendix by $\mathrm{Mr}$. Newstead on the anatomy of the tick (Ornithodoros moubata) which conveys the disease.

1 (I) "The Thompson.Yates and Johnston Laboratories Report." Edited by Rubert Boyce and Charles Sherrington, with $\mathrm{H}$. E. Annelt, Benjamin Moore, Ronald Ross and E. W. Hope. Pp. I4 I. Vol. vi. (New Series), Part ii., December, rgo5.

(2) Ibid. Vol. vii., Part i., February, 1906. Pp. $88+$ plates.

(3) "Rapport sur l'Expédition au Congo, rgo3-5." Par J. Evere't Dutton and John L. Todd. (École de Médicine Tropicale de Liverpool, Mém. xx.) Pp. 7J. (All published for the University Press of Liverpool, Mem. XX.) Pp. 7 . (All published for the University
by Willianss and Norgate, London, 1006.) Price 5 s.

by Willianss and Norgate, London, 1026.) Price $5 s$. P.aboratcries at the Gordon Memorial College, Khartoum." By Andrew Balfour. 